\title{
Systematic Review of the Use of Hospital Administrative Data to Assess Functional Decline
}

\author{
Rao $A^{1^{*}}$, Suliman $A^{2}$, Vuik $\mathbf{S}^{3}$, Darzi $A^{3}$ and Aylin $\mathbf{P}^{1}$ \\ ${ }^{1}$ School of Public Health, Faculty of Medicine, United Kingdom \\ ${ }^{2}$ Department of Surgery and Cancer, Faculty of Medicine, St Mary's Hospital, Imperial College London, United Kingdom \\ ${ }^{3}$ Centre for Health Policy, Institute for Global Health Innovation, Imperial College London, Praed Street, United Kingdom
}

*Corresponding author: Ahsan Rao, School of Public Health, Faculty of Medicine, Dr. Foster Unit, 3 Dorset Rise, London EC4Y 8EN, United Kingdom, Tel: 07505307503; Fax: 02033126309; E-mail: a.rao@imperial.ac.uk

Received date: September 06, 2016; Accepted date: December 09, 2016; Published date: December 10, 2016

Copyright: ( 2016 Rao A, et al. This is an open-access article distributed under the terms of the Creative Commons Attribution License, which permits unrestricted use, distribution, and reproduction in any medium, provided the original author and source are credited.

\begin{abstract}
Introduction: Functional decline is commonly assessed by questionnaire-based surveys; however, administrative data can provide an alternative to evaluate functional decline. The aim of this study was to find out whether administrative data can be used to predict functional decline by conducting a systematic review of the literature.

Methods: The methodology of the systematic review was based on PRISMA guidelines and PICOS process. The included studies were analyzed to identify different methods based on administrative to predict functional decline.

Results: Three predictive models were developed from outcome measures based on administrative data. Firstly, model based on hospital readmissions was used to predict functional decline. Both model and survey results were compared to predict restricted activity days over 4 years' duration. Hospital readmission based model had a predictive accuracy (AUC 0.69) like self-reported surveys (AUC $0.71 \mathrm{p} 0.14$ ). Secondly, procedural claims-based codes were used to construct a model that identified hospital procedures and services associated with functional decline. The model was compared to self-reported information on activities of daily living. It showed sensitivity of 0.79 and specificity of 0.92 . Thirdly, post-operative imaging and reoperation codes were reviewed as predictive indicators, but were found to have no significant association with functional decline.
\end{abstract}

Conclusion: Models based on hospital readmissions have the potential to be used widely because it has significant correlation with functional health and is a commonly recorded outcome measure in HAD. Its predictive accuracy is like self-reported functional health.

Keywords: Administrative data; Functional decline; Predictive modelling

\section{Introduction}

One of the biggest challenges faced by health policy makers is to prevent functional decline in the elderly population [1]. This population is increasing and it is estimated that it will double by the year 2050 [2]. Functional decline, frailty and disability increase with age [3]. It is foreseen that the burden of functional decline and disability will markedly increase soon. In the US, the National Committee on Vital and Health Statistics acknowledged the importance of functional health. It stated that achieving optimal health and wellbeing for Americans requires an understanding across life span of the effects of people's health conditions on their ability to do basic activities and participate in life situations - in other words, their functional status' [4].

It is important to predict patients with functional decline because they are a higher risk of the use of healthcare resources5. Previous prediction models for functional decline have obtained data from questionnaires and surveys, which ask questions about activities of daily living (ADL), such as cooking, bathing, toileting and climbing stairs [5]. Questionnaire-based studies are expensive and difficult to conduct at a population level as everyone must undergo detailed assessment of their functional health. Proxy or self-reporting methods used in these studies rely on patient self-assessment for data collection which cannot be verified objectively. A significant number of these patients suffer from cognitive and mental health disorders, making it difficult to retrieve information for questionnaires. Moreover, data gathered by conducting surveys provides cross-sectional overview with limited follow up.

Administrative data can provide an effective alternative and has the potential to evaluate functional decline [5-9]. Administrative data offers 'system wide information about health conditions and services in a consistently coded format' [4]. It is primarily collected for billing purposes but it can be used for research [5]. It is collected for the entire population, and can be tracked over a long period. The data can be linked to other data sources that can provide additional information, such as patient's demographics, medical history and pharmacotherapy. The data collection is not biased by recall of patients as in self-reported surveys [6]. Systematic diagnostic codes are used to record comorbidities. There are various outcome metrics that are available, for instance, recurrent hospitalization, increased length of stay (LOS), and discharge to nursing home. The aim of the study is to find out whether administrative data can be used to predict functional decline in the patients by conducting a systematic review of the literature. 


\section{Methods}

\section{Search strategy}

The methodology of the systematic review was based on PRISMA guidelines (Figure 1) [10].

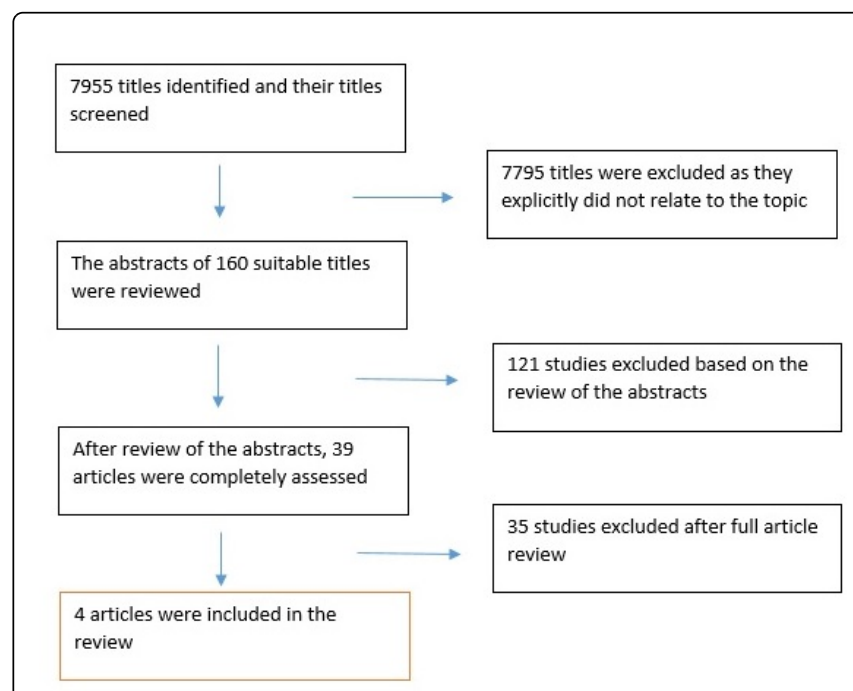

Figure 1: PRISMA diagram for the selection of studies included in the review.

The PICOS process was used to develop the search strategy [10]. The following literature databases were searched: Embase (1945-2015), Medline (1946-2015), Web of Science (1950-2015), Current Contents Connect, and SciELO citation index. Various search terms were used to identify studies involving functional decline and hospital administrative data (Table 1). Boolean terms, like 'OR' and 'AND', were used to combine search terms.

Further studies were identified through cross-referencing of initial studies reviewed. Two independent researchers, AS and AR, reviewed the selected studies separately. Meta-analysis was not conducted because there was significant heterogeneity in the studies.

\section{Inclusion and exclusion criteria}

The following inclusion criteria were used:

1. Participants: adult patient population over the age of 18 diagnosed with any type medical condition.

2. Intervention: The patient admitted to hospital for any medical or surgical condition and underwent any intervention to prevent or reduce functional decline.

3. Comparison was made between studies using HAD and any other method of evaluation of functional decline.

4. Outcome: assessment of functional decline following hospital admission.

5. Study design: studies that used HAD based metrics to derive or validate model to assess functional decline.

The following exclusion criteria were used:

1. Studies that did not use HAD were excluded from the review.

2. Studies that used clinical data from controlled trials, observational studies, case series or clinical registries.

3. Studies only evaluating cost outcomes.

\begin{tabular}{|l|l|}
\hline 1 & "quality of life"/ or functional assessment/ or health status/ or daily life activity/ or functional health.mp. \\
\hline 2 & functional decline.mp. \\
\hline 3 & functional deterioration.mp. \\
\hline 4 & functional impairment.mp. \\
\hline 5 & exp disability/ \\
\hline 7 & data base/ or administrative data.mp. or health services research/ \\
\hline 8 & $\begin{array}{l}\text { (administrative adj data).mp. [mp=title, abstract, heading word, drug trade name, original title, device manufacturer, drug manufacturer, device trade } \\
\text { name, keyword] }\end{array}$ \\
\hline 9 & $\begin{array}{l}\text { (hospital adj administrative adj data).mp. [mp=title, abstract, heading word, drug trade name, original title, device manufacturer, drug manufacturer, } \\
\text { device trade name, keyword] }\end{array}$ \\
\hline 10 & $\begin{array}{l}\text { (billing adj data).mp. [mp=title, abstract, heading word, drug trade name, original title, device manufacturer, drug manufacturer, device trade name, } \\
\text { keyword] }\end{array}$ \\
\hline 11 & hospital readmission/ \\
\hline 12 & exp "length of stay"/ \\
\hline 13 & exp mortality/ \\
\hline 14 & exp falls/ \\
\hline
\end{tabular}




\begin{tabular}{|l|l|}
\hline 15 & hospitalization/ or hospitalization\$.mp. \\
\hline 16 & 1 or 2 or 3 or 4 or 5 \\
\hline 17 & 6 or 7 or 8 or 9 \\
\hline 18 & 16 and 17 \\
\hline 19 & 10 or 11 or 12 or 13 or 14 or 15 \\
\hline 20 & 18 and 19 \\
\hline
\end{tabular}

Table 1: Search strategy used: Web of Science Core Collection, Medline, Current contents connect, KCI- Korean Journal Database, SciELO Citation Index, Embase.

\section{Data collection}

Basic demographics were obtained from each study included in the review. Year of publication, place of data collection, administrative databases used, and aim and objectives of each study were recorded. Information on methodology of each study was collected, such as, number of patients, use of control group, diagnosis of patients, types of outcome measures used, results of significant outcomes, and follow up period.

\section{Assessment of risk of bias}

The Newcastle-Ottawa scale was used to assess bias in the included studies [11]. This scale is validated and recommended by Cochrane review methodological guidelines for non-randomized studies. Criteria for assessing bias associated with the study was based on selection of patients, comparability of methodologies or intervention and clear definition of outcomes measured. A study can get a maximum of $8 / 8$ stars, suggesting minimum bias.

\section{Results}

There was a total of 4 studies included in the systematic review (Table 2). Four studies evaluated functional decline in elderly population [12-14], while the other two studies included adult population over the age of $16[15,16]$. The patient population selection differed in studies; it included community dwelling elderly population [13], patients admitted to inpatient rehabilitative facilities [14,16], patients who underwent spine surgery [15], and stroke patients [14]. The hospital administrative data used by the studies were local Canadian [15] and American [12] hospital administrative databases, and Medicare database [7,13]. The information on ADL for comparison with HAD-based variables was obtained from survey data $[7,13]$ and proxy or self-reported questionnaires $[12,15]$. We identified three predictive models that used HAD to assess functional decline.

\begin{tabular}{|c|c|c|c|c|c|}
\hline Study & Patient characteristics & $\begin{array}{l}\text { Outcomes derived from } \\
\text { administrative data }\end{array}$ & Comparison tool & Outcome & $\begin{array}{l}\text { Newcastle-Ottawa } \\
\text { Score }\end{array}$ \\
\hline $\begin{array}{l}\text { Faurot et al. } \\
\text { [13] }\end{array}$ & Community-dwelling elderly patients, age $>65$ & \begin{tabular}{|lr} 
Procedure & claims-based \\
predictors (use & of \\
diagnostic & and \\
procedural codes). &
\end{tabular} & $\begin{array}{lr}\text { ADL } & \text { dependence } \\
\text { measured by } & \text { survey } \\
\text { data (Medicare } & \text { Current } \\
\text { Beneficiary } & \text { Survey } \\
\text { [MCBS]) } & \end{array}$ & $\begin{array}{l}\text { Predictors of functional } \\
\text { decline were home } \\
\text { hospital bed, wheelchair, } \\
\text { home oxygen, podiatry, } \\
\text { rehabilitation care, } \\
\text { difficulty walking, } \\
\text { dementia, stroke, and } \\
\text { heart failure. }\end{array}$ & $* * * * * *$ \\
\hline $\begin{array}{l}\text { Coleman et al. } \\
\text { [12] }\end{array}$ & Elderly population, age>65 & $\begin{array}{l}\text { Previous readmission } \\
\text { rate }\end{array}$ & $\begin{array}{l}\text { Self-reported survey } \\
\text { (SF-36) }\end{array}$ & $\begin{array}{l}\text { The c-statistics for } \\
\text { functional decline using } \\
\text { administrative indices } \\
\text { was } 0.69\end{array}$ & 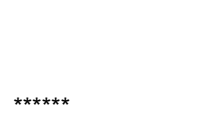 \\
\hline $\begin{array}{l}\text { Davidoff et al. } \\
\text { [7] }\end{array}$ & Elderly patients & $\begin{array}{lr}\text { Procedural claims-based } \\
\text { predictors (use } r \text { of } \\
\text { diagnostic } & \text { and } \\
\text { procedural codes). }\end{array}$ & 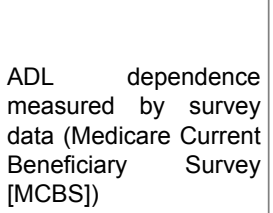 & $\begin{array}{lrr}\text { Positive indicators of } \\
\text { poor disability } & \text { status: } \\
\text { nursing home r stays, } \\
\text { home care and } \\
\text { ambulance use. Model } \\
\text { sensitivity (0.79) and } \\
\text { specificity }(0.92) .\end{array}$ & $* \star \star *$ \\
\hline $\begin{array}{l}\text { Omoto et al. } \\
{[15]}\end{array}$ & $\begin{array}{l}\text { All patients who underwent discectomy, } \\
\text { decompression (laminectomy/laminotomy) or } \\
\text { fusion for disc herniation }\end{array}$ & $\begin{array}{l}\text { Post-operative } \\
\text { outcomes (imaging and } \\
\text { re-operation rate) }\end{array}$ & $\begin{array}{l}\text { Self-reported } \\
\text { questionnaire (SF 36) }\end{array}$ & $\begin{array}{l}\text { Reoperation and PCSI } \\
\text { were not associated with } \\
\text { functional decline. }\end{array}$ & $* * *$ \\
\hline
\end{tabular}

Table 2: Characteristics of studies included in the review. 
Page 4 of 5

\section{Hospital readmissions}

Coleman et al. aimed to compare predictive accuracy of two indices for functional decline, one based on hospital administrative data and the other on self-reported questionnaire [12]. There were 1,764 patients included in the study and they were followed up for 4 years. The previous number of readmissions were used as an outcome measure from HAD to predict functional decline. Self-reported functional status was measured using SF-36 questionnaire. The outcome measure was prediction of restricted activity days (RAD), which was derived from cumulative length of stay in hospital for patients for every following year. The predictive accuracy for the model based on readmissions obtained from the administrative variables was not significantly different from self-reported model for functional health. The Area Under the Curve (AUC) depicting predictive accuracy of administrative model was 0.691 as compared to 0.714 for self-reported model $(\mathrm{P}=0.144)$.

\section{Procedural claims-based predictors}

Davidoff et al. and Faurot et al. created a predictive model based on different types of procedures and medical equipment that patients undergo and use. The studies were conducted on the elderly patient population over the age of $65[7,13]$. The studies extracted information from US-based administrative data, CMS (Centers for Medicare and Medicaid Services). The data includes the type of services provided and procedures conducted on each patient. The procedures were coded in various formats: ICD-9, the American association Current Procedural Terminology (CPT) and CMS Healthcare Common Procedure Coding System (HCPCS). The outcome measure was self-reported information on decline in ADL and mobility. It was obtained from CMS data linked to Medicare Current Beneficiary Survey (MCBS) and was used to validate the predictive model.

Davidoff et al. conducted their study on 7,394 patients and used it to predict functional decline as a proxy for performance status in cancer patients, whereas, Faurot et al. built their model to predict functional decline as a proxy for frailty in 6391 patients. Davidoff et al. showed that the positive indicators of functional decline were nursing home stays, home care and ambulance use. Model based on these indicators showed high sensitivity (0.79) and specificity (0.92). Similarly, Faurot et al. showed that predictors of functional decline were use of home hospital bed, wheelchair, home oxygen, podiatry, rehabilitation care, difficulty walking, dementia, stroke, and heart failure.

\section{Post-operative outcomes}

Omoto et al. assessed the use of PCSI (post-operative crosssectional imaging) and reoperation as predictive indicators for functional decline [15]. The use of PCSI included either magnetic resonance imaging (MRI) or computed tomography with myelography (CT-myelogram). It was proposed that the use of PCSI and reoperation were associated with functional decline in patients who underwent spinal surgeries (discectomy, decompression (laminectomy/ laminotomy) or fusion for disc herniation). The model was validated by comparing it to questionnaire-based functional outcome measures (SF-36 and Oswestry disability index). There were 148 patients included in the study and the patients were followed up for 2 years. There was no significant relationship between the occurrence of PCSI or reoperation and functional decline.

\section{Discussion}

\section{Summary of results}

The review was based on 6 studies that developed 3 predictive models based on HAD quality metrics to assess functional health. Hospital readmission and specific procedural codes based on HAD were used as a proxy to measure functional health. They showed significant correlation with functional decline. The model based on PCSI and reoperation did not show any significant association with functional health. The study population, type of administrative data, and outcome measures differed in the studies included in the review. Similarly, studies in the review had variable ranking based on the Newcastle-Ottawa scale for assessment of bias. Common reasons for high risk of bias were inadequate follow-up and not clearly defined comparison group $[7,15]$. Two models assessed functional health but used this as a proxy to measure performance status and frailty [13].

\section{Comparison with previous studies}

Previous studies have shown strong link between hospital readmissions and poor quality of life $[12,16]$. Patients with higher number of hospital readmissions had prolonged length of stay in the hospital every year and suffered higher morbidity [14]. They were also associated with increased risk of discharge to nursing home [11]. Hospital readmissions directly impact functional status of the patient as shown in the previous studies where annual survey was conducted at the rehabilitative hospitals [12]. Each hospital admission cause loss in muscle and bone density, put one at an increased risk of dehydration and malnutrition, and risk of iatrogenic injuries. All these conditions can lead to patient having falls, fractures and delirium. These patients lose the ability to cope at home and require further readmissions [12].

In addition, hospital readmission is one of the most commonly recorded HAD based metric. This information is commonly extracted and used in different studies to assess patient outcome and used as a marker of poor health status [17-19]. Similarly, our review showed that the predictive model based on hospital readmission had better sensitivity and specify than the other models. The accuracy to predict functional decline for model based on hospital readmissions was like self-reported questionnaire.

Predictive models based on FIM score and FIS staging had limited applicability for National and International comparison of functional outcome as observed in previous studies [19]. In general hospitals, there are no regulations to record ADL [14]. Its current use is limited to specific institutions and regions because the recording of FIS requires a significant time investment by trained nursing staff at the time of admission and discharge of the patient [15]. The recording of ADL is conducted in hospitals based on financial incentives give to them. Similarly, in our review, FIS score was derived from information on ADL collected by administrative databases of rehabilitative hospitals [14]. It is still to be investigated how these scores are recorded in busy general hospitals where turnover is fast and patients are moved from one unit to another.

\section{Strengths of the review}

This review attempted to combine limited data available on the measurement of functional health using HAD based outcomes. Certain models were identified that could potentially be used to study functional health. Various databases were searched to identify studies 
that could be included in the review. Newcastle-Ottawa scale was used to measure bias associated with the studies. This review suggests that further research is required to completely assess potential of administrative data to evaluate functional decline. The combination of outcomes, such as length of stay, discharge destination and causespecific readmission rate, may provide better predictive ability to assess functional decline. Although discharge destination, LOS and mortality were other outcome measures based on HAD that had been used in previous clinical studies to assess impact of various treatments on patient's health but they had not been assessed for their direct association with functional health $[7,12,14,16]$. Once it can be shown that outcomes based on HAD can be used as a validated proxy measure for functional health, its application can be implemented at a larger scale as in most Western countries hospital administrative data is routinely and annually collected. It can be used to study trends in the changes in functional health at a population level and help assess clinical factors and interventions that can prevent functional decline.

\section{Limitations of the review}

There were limited studies that assessed the role of administrative data to study functional decline, hence, the number of studies included in the review is small. There was significant heterogeneity among the included studies. They had different outcomes measures, tools to validate predictive model, and patient cohorts. It was not possible to combine the results and perform meta-analysis of the outcome. The studies that used claims-based codes as a marker for functional decline has limited generalizability [13]. It is still uncertain how often the information on health care service utilization and procedural codes is recorded in different regions. Coding of certain procedures is not widespread and vary in different databases [13].

The use of coding for post-operative cross-sectional imaging (PCSI) and reoperation as a proxy measure of poor functional health in lumbar spine patients was investigated but it was not found have any significant correlation [15]. The authors concluded that reoperation rate was a poor marker as significant numbers of lumbar spine patients undergo a planned second operation. These metrics therefore have limited use as a proxy measure for functional health.

\section{Conclusion}

Three predictive models have been developed to assess functional decline based on outcomes derived from hospital administrative data. Models based on hospital readmissions have the potential for widespread use because it had significant correlation with functional decline. Its predictive accuracy was like self-reported functional health. However, further studies are required to completely assess potential of administrative data to evaluate functional decline.

\section{Author Statement}

As it is a review paper based on previous published studies, no ethical approval was required. The study did not receive any funding. All authors declare no conflict of interest.

\section{References}

1. Clark DO, Stump TE, Hui SL, Wolinsky FD (1998) Predictors of mobility and basic ADL difficulty among adults aged 70 years and older. J Aging Health 10: 422-440.
2. Chatterji S (2013) World Health Organisation's (WHO) Study on Global Ageing and Adult Health (SAGE). BMC proceedings.

3. Abizanda P, Romero L, Sanchez-Jurado PM, Martínez-Reig M, AlfonsoSilguero SA, et al. (2014) Age, frailty, disability, institutionalization, multimorbidity or comorbidity. Which are the main targets in older adults?. J Nutri Health Aging 18: 622-627.

4. Iezzoni L, Greenberg M (2003) Capturing and classifying functional status information in administrative databases. Health Care Financ Rev 24: 61-76.

5. Dewa CS, Chau N, Dermer S (2009) Factors Associated With Short-Term Disability Episodes. J Occup Environ Med 51: 1394-1402.

6. Fulton-Kehoe D, Gluck J, Wu R, Mootz R, Wickizer TM, et al. (2007) Measuring work disability: What can administrative data tell us about patient outcomes? J Occup Environ Med 49: 651-658.

7. Davidoff AJ, Zuckerman IH, Pandya N (2013) A novel approach to improve health status measurement in observational claims-based studies of cancer treatment and outcomes. J Geriatr Oncol 4: 157-165.

8. Feliciano J, Gardner L, Hendrick F, Edelman MJ, Davidoff A, et al. (2015) Assessing functional status and the survival benefit of chemotherapy for advanced non-small cell lung cancer using administrative claims data. Lung Cancer 87: 59-64.

9. Hastings SN, Purser JL, Johnson KS, Sloane RJ, Whitson HE, et al. (2009) Frailty predicts some but not all adverse outcomes in older adults discharged from the emergency department. J Am Geriatr Soc 56: 1651-1657.

10. Moher D, Shamseer L, Clarke M, Ghersi D, Liberati A, et al. (2015) Preferred reporting items for systematic review and meta-analysis protocols (PRISMA-P) 2015 statement. Systematic reviews 4: 1-1.

11. Higgins JPT, Altman DG, Gotzsche PC, Jüni P, Moher D, et al. (2011) The cochrane collaboration's tool for assessing risk of bias in randomised trials. Br Med J 343: d5928.

12. Coleman EA, Wagner EH, Grothaus LC, Hecht J, Savarino J, et al. (1998) Predicting hospitalization and functional decline in older health plan enrollees: Are administrative data as accurate as self-report? J Am Geriatr Soc 46: 419-425.

13. Faurot KR, Funk MJ, Pate V, Brookhart MA, Patrick A, et al. (2015) Using claims data to predict dependency in activities of daily living as a proxy for frailty. Pharmacoepidemiol Drug Saf 24: 59-66.

14. Brown AW, Therneau TM, Schultz BA, Niewczyk PM, Granger CV (2015) Measure of Functional Independence Dominates Discharge Outcome Prediction After Inpatient Rehabilitation for Stroke. Stroke 46: 1038-1044.

15. Omoto D, Bederman SS, Yee AJM, Kreder HJ, Finkelstein JA, et al. (2010) How do validated measures of functional outcome compare with commonly used outcomes in administrative database research for lumbar spinal surgery? Eur Spine J 19: 1369-1377.

16. Neuman MD, Silber JH, Magaziner JS, Passarella MA, Mehta S, et al. (2014) Survival and Functional Outcomes After Hip Fracture Among Nursing Home Residents. JAMA Intern Med 174: 1273-1280.

17. Stineman MG, Ross RN, Fiedler R, Granger CV, Maislin G, et al. (2003) Staging functional independence validity and applications. Arch Phys Med Rehabil 84: 38-45.

18. Hoogendijk EO, van Hout HPJ, van der Horst HE, Frijters DH, Dent E, et al. (2014) Do psychosocial resources modify the effects of frailty on functional decline and mortality? J Psychosom Res 77: 547-551.

19. Jette D, Warren R, Wirtalla C (2005) Validity of functional independence staging in patients receiving rehabilitation in skilled nursing facilities. Arch Phys Med Rehabil 86: 1095-1101. 